\title{
El riesgo de una mala comunicación de riesgos
}

\section{The Risks of Bad Risk Communication}

\author{
Joan Carles March Cerdá \\ (Granada, España) \\ Escuela Andaluza de Salud Pública
}

\begin{abstract}
Cómo citar el artículo
March Cerdá, J. C. (2011). El riesgo de una mala comunicación de riesgos. Revista de Comunicación y Salud, 1(2), pp. 61-66.

DOI: http://doi.org/10.35669/revistadecomunicacionysalud.2011.1(2).61-66
\end{abstract}

Alemania tuvo un problema que no supo resolver. Europa tiene un problema de salud pública, coordinación y comunicación que no está sabiendo resolver. En Alemania tuvieron un problema por las personas que fallecieron debido a la infección letal de la bacteria Escherichia coli. En Alemania hubo un problema con más de 2.500 afectados o con síntomas.

Y la verdad es que las autoridades alemanas y europeas tuvieron un problema en el sistema de alerta sanitaria. Todo fueron errores. Primero apuntaron al pepino español como causante del brote infeccioso, focalizado en Hamburgo, lo cual ocasionó un problema importante a los agricultores andaluces y a la economía española en general. Más tarde investigaron varios restaurantes de la localidad de Lübeck. Luego las sospechas apuntaban hacia una explotación de brotes de soja de Baja Sajonia y así sucesivamente, demostrando una deficiente vigilancia epidemiológica y una mala comunicación de la situación de crisis tanto mediáticamente como en los grupos de población específicos.

Como afirman Ricard Meneu y Juan Gérvas, las crisis sanitarias están aquí para quedarse, y 
nuestra voluble percepción de riesgos las hará más frecuentes e impredecibles. Un sistema sanitario atento a las necesidades de la población está obligado a perfeccionar los instrumentos para garantizar una adecuada preparación ante sus eclosiones. Siendo realistas, la percepción de las crisis será cada día más ajena a los expertos y más determinada por colectivos interesados en propagarlas o aportar soluciones. Lidiar con ello exige una difícil ponderación entre la necesidad de articular respuestas y la de desactivar temores poco fundados o magnificados.

\section{¿Cuáles son los errores más habituales de una comunicación de riesgos, de una crisis en salud?}

Existen 5 errores que se deben considerar en una situación como la que ocurrió en el caso de Alemania:

1. La no identificación de una persona que dé la cara, que sea la portavoz o que quien hace de portavoz lo haga sin preparar, sin pensar en las consecuencias de sus intervenciones.

22 de mayo. Alemania informó de un aumento significativo en el número de pacientes con síndrome urémico hemolítico y diarrea con sangre causadas por E. coli. Un día después, Cornelia Prüfer-Storcks, consejera de Salud del Estado-Ciudad de Hamburgo afirmó que los pepinos importados de España eran la fuente de la epidemia. Y con ello, España apareció en dos terceras partes de todas las noticias en relación con la crisis de E.coli y fue el segundo país más vinculado a la crisis en las noticias. Alrededor de 7.000 artículos citaron los pepinos de España como causa de la epidemia. Este número muestra lo poderoso que fue el eco de las acusaciones. Las referencias a España en los países latinoamericanos fueron más altas que el promedio internacional.

Es fundamental tener en cuenta que la mejor improvisación es la cuidadosamente preparada y que la preparación ante la crisis es punto clave en su resolución.

2. El no conocimiento de los hechos en profundidad, la no anticipación de los posibles escenarios futuros y la infravaloración de las percepciones externas tanto de la población como de agentes clave (agricultores, consumidores, responsables de otros países...). Asimismo es básico tener en cuenta que estamos en una sociedad mediática, una sociedad en red, donde todo se puede conectar y ello facilita su potencial desarrollo informativo. La realidad mediática no parte de cero sino sobre el imaginario colectivo previo en el cual reposa. Y además, cuanto mayor es la percepción de amenaza, mayor es la demanda de respuesta preventiva y en el caso de las amenazas sanitarias o alimentarias, prácticamente no hay tolerancia, cosa que las autoridades saben, lo cual hace que actúen compulsivamente (como en el caso alemán).

Encontrar la fuente de la infección es vital para restaurar la serenidad de las opinión pública. Y también es importante trabajar en auditorías de riesgo o de vulnerabilidad y ver hasta qué punto uno tiene que actuar para atenuar los efectos negativos de un posible riesgo. 
3. La no existencia de un mensaje único y consensuado con una adecuada estrategia de comunicación con los medios y con los diversos públicos afectados.

4. La falta de rapidez en dar la información a partir del conocimiento básico de los hechos que ocurrieron, la puesta en marcha del comité anticrisis, trabajando desde el primer momento, preparado y que centralizara la información.

En una crisis sanitaria o medioambiental, si una organización no actúa con rapidez, es que no estaba preparada; si no se anticipa a las circunstancias, es que no está siendo eficaz y si no es capaz de transmitir la información de forma transparente, puede ser que tenga algo que ocultar o al menos esto es la idea que se genera entre la población.

5. Y la preponderancia de los políticos frente a comités asesores expertos en la materia, a la hora de explicar a la población lo que estaba pasando en ese momento y las consecuencias de lo que había pasado. No se entiende en Europa que el European Center of Disease Control no tenga un papel más relevante en estas situaciones.

La frecuente práctica de una gestión distante y poco transparente de los políticos les recorta crédito y confianza de la población, de los pacientes y de los profesionales (clínicos y salubristas), como dice Ildefonso Hernández. En general, su comportamiento se guía por el corto plazo y por el impacto electoral.

En la percepción del riesgo, es importante tener en cuenta el liderazgo y credibilidad de quien hace de portavoz y del papel de los políticos y técnicos ante la opinión; la investigación rigurosa, con celeridad y que tenga en cuenta las distintas percepciones; la participación de la población, de las asociaciones, de las personas afectadas; la intervención teniendo en cuenta el miedo y las expectativas de la población, junto a directrices claras e información fiable; y la información de los medios de comunicación. Y eso implica, respeto, coordinación y una institución con peso científico ante la población y ante los medios de comunicación que actuara de portavoz ante situaciones de riesgos en una organización, para conseguir la confianza de la gente.

La capacidad técnica de los profesionales sanitarios está más acreditada que la de los responsables públicos, lo que aconseja una mayor participación de los primeros y una mejor capacitación de los segundos.

Y como decía Milagros Pérez Oliva, las crisis globales plantean un problema de autoridad. ¿Quién ejerce la autoridad en un mundo con responsabilidades fraccionadas? Los referentes globales tienen aún poca fuerza y en un mundo que tiende a vincular la autoridad con la fuerza, con frecuencia las crisis globales presentan un déficit de autoridad. La crisis de salud deriva a menudo en una crisis de autoridad.

Y la realidad es que desde aquel momento, Alemania, España y Europa padecieron una mala comunicación de riesgos, ya que por una mala comunicación se provocó el pánico... y explotó la cobertura de los medios de comunicación. Y es que las crisis tienen impacto en la reputación. 


\section{Las crisis anteriores y su gestión}

En el imaginario colectivo es evidente que queda el pepino, como quedó la vaca, como quedó la gripe, como quedó el aceite de colza, como quedó el Prestige. Y la pregunta que se hace el epidemiólogo Miquel Porta es muy válida: las crisis ¿han aumentado la fortaleza y la credibilidad de los sistemas de salud pública, seguridad alimentaria y medio ambiente de la Unión Europea?, ¿están sirviendo las crisis para cambiar a mejor las características estructurales de tales sistemas?, ¿son estos sistemas culturalmente y ecológicamente sostenibles?, ¿han ido a mejor en 10 años? Y esto se lo planteaba hace más de 3 años. Y en otro aspecto, la coordinación entre recursos es un aspecto clave en la preparación y respuesta proporcional a la crisis. Hace 10 años, un titular de periódico decía lo siguiente "La rotura de una presa con agua ácida causa un desastre ecológico en Doñana". Era abril de 2008 cuando el Ministerio de Sanidad escribía una nota en la que, "como medida transitoria, y en cumplimiento del principio de precaución, el Ministerio de Sanidad y Consumo recomienda, en primer lugar, no consumir aceite de girasol". Son dos ejemplos de muchas crisis, de muchas situaciones de riesgo, de mucha percepción de estar ante situaciones sanitarias que generan incertidumbre y miedo. La epidemia del miedo que generó la meningitis, la crisis de las vacas locas, los brotes de legionella, las crisis alimentarias habituales, el caso de la gripe aviar, los problemas de la ola de calor o la catástrofe del Prestige han ocupado páginas y páginas de periódicos, preocupaciones ciudadanas y ocupaciones de políticos y técnicos en su gestión y actuación.

Todas esas situaciones nos muestran un problema común: la importancia de tener en cuenta la percepción del riesgo que tiene la población ante una situación determinada y en segundo lugar, la necesaria comunicación que hay que establecer en situaciones de crisis.

La comunicación de riesgos es el intento que hacen científicos o profesionales para aportar información que permita a una persona, a los interesados directos o a toda una comunidad tomar las mejores decisiones posibles para su bienestar cuando surge una crisis o un posible riesgo para su salud. La comunicación de crisis es el tipo de comunicación del riesgo que se hace cuando tanto el miedo como el peligro son elevados y sirve para ayudar a la gente a soportar sus sentimientos y a superar eficazmente los peligros.

La meta es comunicarse con el público de forma tal que se cree, se mantenga o se restablezca la confianza. Para favorecer la confianza, debe establecerse el triángulo de la confianza, entre políticos, personal técnico y profesional, y comunicadores. La confianza del público necesita de franqueza, competencia, que se responda a sus preocupaciones, y transparencia. Y para dar transparencia, es necesario prometer y cumplir las promesas, informar regularmente y hacer un buen primer anuncio de la situación (es crucial) con empatía, acción y respeto, y no insistir en dar excesiva seguridad, sino preocupación, interés y acción.

Algunos pasos estratégicos necesarios que hay que dar para que la crisis sea controlada lo más pronto posible:

1. Conocer a los hechos.

2. Convocar el equipo de gestión anticrisis, que previamente debe de haber tenido reuniones para poder funcionar de forma armónica y rápida lo antes posible, haber trabajado 
escenarios posibles y tener claro los aspectos de vulnerabilidad más evidentes.

3. Seleccionar un portavoz con formación en comunicación pública y que utilice de forma adecuada, clara y precisa los argumentarios preparados previamente por el equipo de gestión anticrisis.

4. Montar un centro de gestión anticrisis, cercano al lugar de la crisis.

5. Establecer una unidad de control para saber qué se está diciendo sobre la crisis.

6. Movilizar los recursos necesarios para poder responder de forma rápida y adecuada.

7. Establecer una estrategia de medios informativos.

8. Informar a los implicados por diversos canales, en el lugar adecuado, por los portavoces precisos.

9. Establecer comunicaciones in situ, con palabras mágicas (bueno, solución, fácil,..) y pocas palabras trágicas (muerte, difícil, problema, pega, alarma, gravedad,...) para ayudar a los receptores de la comunicación.

10 Identificar la posición adecuada una vez terminada la crisis.

Para terminar ahí van 17 medidas y alguna más para una estrategia de comunicación de riesgos adecuada:

1. No sobretranquilizar.

2. Tener en cuenta la situación de alarma.

3. Reconocer la incertidumbre.

4. Plantear escenarios y dilemas posibles.

5. Reconocer la diversidad de opiniones.

6. Estar dispuesto a especular.

7. No aspirar al miedo cero.

8. Legitimar miedos de la gente.

9. Tolerar tempranas reacciones exageradas.

10. Establecer contacto con el público.

11. Decir a la gente qué se puede esperar.

12. Proponer a la gente qué cosas hacer.

13. Preguntar más a la gente.

14. No mentir y no decir verdades a medias.

15. Aspirar a la calidez, emoción y transparencia.

16. Tener cuidado con comparaciones de riesgo.

17. ¡Y más, mucho, mucho más!

La percepción del riesgo es una cuestión subjetiva. En esta sociedad del espectáculo, cabe esperar un incremento de nuevas crisis sanitarias, y por ello un aprendizaje a una mejor gestión comunicativa de ellas. En muchas crisis sanitarias hay ganadores y perdedores inesperados. Las crisis son retos de los que debemos aprender, tanto de errores como de éxitos, y así perfeccionar nuestra respuesta ante otras próximas, inevitables e impensables crisis. 
Referencias

Porta, Miquel y Morabia, Alfredo. (2004). Why aren't we more ahead? The Risk of Variant Creutzfeldt-Jakob Disease from Eating Bovine Spongiform Encephalopathy-Infected Foods: Still Undetermined [Editorial]. European Journal of Epidemiology. Vol. 19, n 4, pp. 287-289. doi: 10.1023/B:EJEP.0000024787.22873.cf

Fernández, Karoline; Ciotti, Massimo y Kaiser, Reinhard. (2006). La Unión Europea ante las crisis sanitarias. Revista de Administración Sanitaria. Vol. 4, nº 3, pp. 425-435.

Organización Panamericana de la Salud (OPS). Relaciones con los medios de comunicación en situaciones de emergencia. Disponible en http://www.paho.org/Spanish/ped/medios.htm. Recuperado el 11 de julio de 2011.

Opinión Quiral. (2011). Comunicación sanitaria. Gripe $A . N^{\circ}$ 31.1. Disponible en http://www.fundaciovila casas.com/es/proyecto_salud/opinion_Quiral?buscar=true\&anyo=2011. Recuperado el 16 de julio de 2011.

Porta, Miquel; Casal Lareo, Amparo y Castaño-Vinyals, Gemma. (2004). El impacto en la salud humana de la catástrofe del Prestige. Gaceta Sanitaria. Vol. 18 (Supl. 1), pp. 245-249.

Aboal Viñas, José Luis y Farjas, Pilar. (2001). Legionella: un problema de salud pública y un problema para la salud pública. Gaceta Sanitaria. Vol. 15, pp. 91-94.

Bellaby, Paul. (2003). Communication and Miscommunication of Risk: Understanding UK Parents Attitudes to Combined MMR Vaccination. British Medical Journal. Vol. 327, pp. 725-728. doi: $10.1136 / \mathrm{bmj} .327 .7417 .725$

Slovic, Paul. (1987). Perception of Risk. Science. Vol. 236, pp. 280-285. doi: 10.1126/science.3563507 